\title{
Electrodeposition of Nickel onto 12K Carbon Fibre Tow in a Continuous Manner
}

\author{
Boguslaw Pierozynski \\ Department of Chemistry, Faculty of Environmental Management and Agriculture, \\ University of Warmia and Mazury in Olsztyn, Plac Lodzki 4, 10-957 Olsztyn, Poland \\ (E-mail: bogpierozynski@yahoo.ca)
}

RECEIVED AUGUST 9, 2010; ACCEPTED DECEMBER 17, 2010

\begin{abstract}
Nickel-coated carbon fibre (NiCCF) is an important composite material, which finds numerous engineering applications, primarily within: computer, telecommunication, automotive and military industries. In general, NiCCF can be produced by one of the three methods, namely: chemical vapour deposition (CVD), electroless, and electrochemical (galvanic) deposition of $\mathrm{Ni}$ on a carbon fibre tow material. The present paper reports a study of the process of nickel electrodeposition (at ultrathin layers of $\approx 0.3-0.5 \mu \mathrm{m})$ onto the surface of $12 \mathrm{~K}$ (12000 single filaments) carbon fibre (CF) tow, carried-out in a continuous way. In addition, the effect of selected pre-treatments applied to carbon fibre, as well as that of operational parameters of the process, on the quality of the NiCCF product were investigated. (doi: $10.5562 /$ cca1743)
\end{abstract}

Keywords: nickel-coated carbon fibre, $\mathrm{NiCCF}$, nickel electrodeposition, $\mathrm{CF}$ pre-treatments

\section{INTRODUCTION}

Carbon fibre (CF) and nickel-coated carbon fibre (NiCCF) materials are of primary interest to a number of industry sectors. One of the most important applications for such materials is their utilization in electrostatic dissipation (ESD) and electromagnetic shielding interference (EMI) technologies. These technologies are especially important for automotive, cell-phone, laptop computer and military industry markets. ${ }^{1-5}$ Other reported applications for carbon fibre-based materials involve electrochemical corrosion processes and lithium-ion battery technologies. ${ }^{6-8}$

Nickel-coated carbon fibre composites can be produced by means of chemical vapour deposition (CVD) method, ${ }^{9}$ electroless ${ }^{10-13}$ or by electrochemical deposition of nickel layer onto the surface of carbon fibre tow material. Originally, the commercial process of $\mathrm{Ni}$ electrodeposition on $12 \mathrm{~K}$ carbon fibre tow was extensively studied by L. Morin of American Cyanamid company. The Cyanamid technology (protected by the US patent law) $)^{14-19}$ is a several-step, Watts bath-based $\mathrm{Ni}$ deposition process. According to this invention, ${ }^{14}$ an initial stage of metal electrodeposition (nucleation phase) is realized through application of high external voltages, in order to provide uniform nucleation with the fibrils. As the surface of CF filaments is not very homogeneous throughout the tow, it is therefore very likely that numerous (present) active sites might require different levels of activation energy for this process. The described voltage levels are between 10 and $50 \mathrm{~V}$, and electric charge in the amount of $600 \mathrm{C} / 1000$ fibre strands, at $30 \mathrm{~V}$. The single plating cell of the Cyanamid system consists of a cylindrical electrolyte tank, a series of contact and non-contact rollers, and several anode baskets, containing electrolytic nickel pellets. The reported operational line speed is $1.5 \mathrm{~m} \mathrm{~min}^{-1}$ and thickness of suchproduced Ni deposit (for $7 \mu \mathrm{m}$ in diameter 12K fibre tow) about $0.5 \mu \mathrm{m}$. It has to be stated, how- ever, that the description of the Cyanamid process (given in Refs. 14 through 19) is quite superficial and does concern a largescale (80 tow), commercial plating process.

On the other hand, current study reports a small (single tow) laboratory-size CF electroplating system, which in principal was set to study the effect of basic CF pretreatments, working parameters of the plating setup and the plating bath composition on the quality of such-produced NiCCF composite material. Some of the most important parameters that have been addressed in this work are the following:

- quality and initial condition of carbon fibre precursor,

- fibre passage system: fibre unwinding, cell passage and take-up assemblies, 
- fibre spreading (optimization of the CF tow spreading within an electroplater),

- electrochemical and other parameters, and cell design (current-density and voltage, design of fibre contact and non-contact roller assemblies, internal cathode-to-anode distances, bath composition, operational $\mathrm{pH}$ and temperature parameters, electrolyte circulation, etc.).

\section{EXPERIMENTAL}

A laboratory system for electrodeposition of $\mathrm{Ni}$ on a single tow of $12 \mathrm{~K}$ carbon fibre material (see Figure 1) consists of the following elements:

- fibre pay-out assembly,

- $\quad$ PVC-made fibre electroplating unit (including two dc $10 \mathrm{~A} / 20 \mathrm{~V}$ power supplies, with current resolution of $10 \mathrm{~mA}$ ),

- fibre rinse station (run on distilled $\mathrm{H}_{2} \mathrm{O}$ ),

- fibre drying station (hair dryer-based chamber) and

- motorized spool take-up assembly.

The PVC electroplating unit (see Figure 2) was built for the purpose of this work. The plating unit allowed to study $\mathrm{Ni}$ electrodeposition process in single and double-cell configurations, with adjustable effective cell lengths of 2.5, 5 and $8 \mathrm{~cm}$ (first cell), and 5 and 10 $\mathrm{cm}$ for the second cell. The electroplater was designed to operate at current-densities ranging from 5 to $50 \mathrm{~mA}$ $\mathrm{cm}^{-2}$, resulting voltages $\approx 2-10 \mathrm{~V}$ (for the first cell) and the plating line speed between 10 and $100 \mathrm{~cm} \mathrm{~min}^{-1}$. Two DSA $(\mathrm{Nb}$ clad $\mathrm{Pt})$ anodes per cell $(20 \times 20$ and $45 \times 20 \mathrm{~mm}$ strip type, with adjustable separation gap of 10 to $20 \mathrm{~mm}$ ) were used. Two sets of highly-polished (20 mm in diam.), stainless-steel (SS) and/or Cu cathodic contact rollers (pinch or wrap configuration, see Figure 3) per each deposition cell were employed, with flexible adjustment of the distance $d$ between the cathodic contact points and an entrance (or exit) of the plating chamber. In addition, the electroplater was equipped with four sets of electrolyte sprinklers, coupled with an original design of electrolyte overflow compartments, aimed both at minimizing the $d$ parameter, as well as the effect of electrolyte splashing outside the plating cells. The fibre pay-out assembly consisted of a regular CF $12 \mathrm{~K}$ spool (Hexcel $12 \mathrm{~K} \mathrm{AS} 4$ product), several $10 \mathrm{~cm}$ in diam. PTFE-made fibre lead rollers and three, $5 \mathrm{~cm}$ in diam. $\mathrm{Cu}$ (or SS)-made fibre spreading contact rollers. The tension for the CF tow was arbitrarily set through adjustment of the clutch on the pay-out spool assembly. Similar design was employed on the motorized, cross-winding take-up end of the fibre plating system.

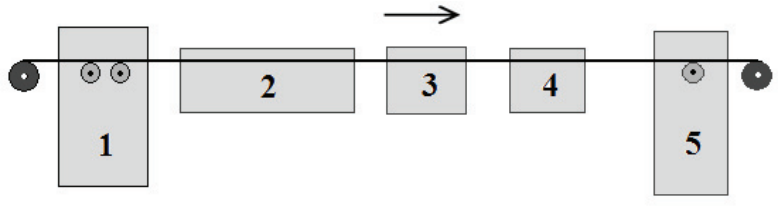

Figure 1. Schematic diagram of a laboratory-size carbon fibre electroplating line, where the following elements are: fibre pay-out and spreading assembly (1); electroplating cell assembly (2); fibre rinse station (3); fibre drying station (hair dryerbased) (4); and fibre take-up assembly (5).

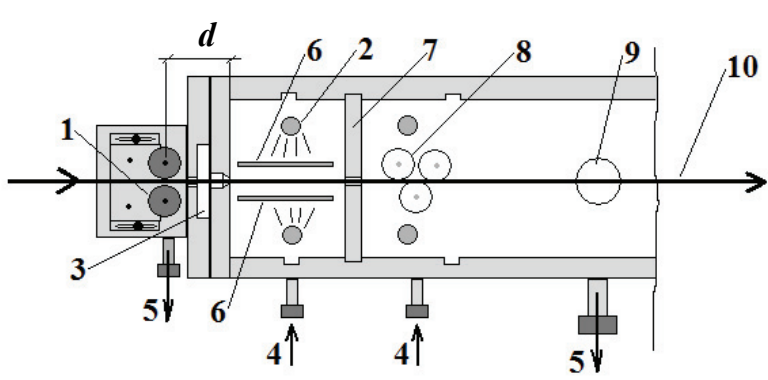

Figure 2. A PVC-made carbon fibre electroplating unit, where the following components are: spring-loaded, adjustable pinch type cathodic CR assembly (1); electrolyte sprinkler (2); electrolyte overflow compartment (3); electrolyte circulation (in) (4); electrolyte circulation (out) (5); DSA anode assembly (6); adjustable wall (7): adjustable, wrap type cathodic CR assembly, mounted on electroplater's top cover (8); electrolyte drain (9); CF tow's passage (10); distance between an initial cathodic contact point and entrance of the nucleation plating compartment $(d)$.
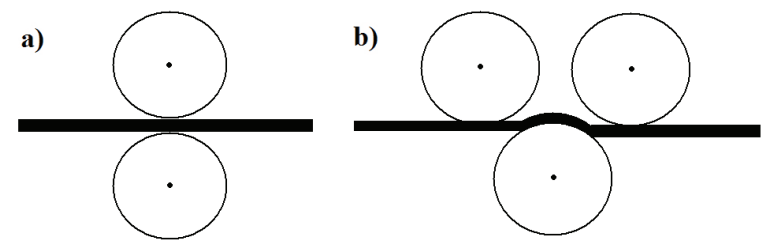

Figure 3. Cathodic contact rollers, shown in pinch (a) and wrap (b) configurations.

A typical Watts ${ }^{20,21}$ nickel plating bath was selected for the purpose of this work. Base electrolyte contained $300 \mathrm{~g} \mathrm{~L}^{-1} \mathrm{NiSO}_{4} \cdot 6 \mathrm{H}_{2} \mathrm{O}, 50 \mathrm{~g} \mathrm{~L}^{-1} \mathrm{NiCl}_{2} \cdot 6 \mathrm{H}_{2} \mathrm{O}$ and $40 \mathrm{~g} \mathrm{~L}^{-1} \mathrm{H}_{3} \mathrm{BO}_{3}$. In addition, two bath additives (wetting agent: $\mathrm{Na}$ lauryl sulphate and $\mathrm{Ni}$ grain refiner: $\mathrm{Na}$ saccharine, in the amount of $0.1-0.5 \mathrm{~g} \mathrm{~L}^{-1}$ and $0.5-1.0$ $\mathrm{g} \mathrm{L}^{-1}$, correspondingly) were also tested. Plating temperature varied between 45 and $60{ }^{\circ} \mathrm{C}$, and $\mathrm{pH}$ was kept between 3.0 and 5.0. As pH of the plating bath continued to decline upon Ni electrodeposition, this parameter was constantly monitored during the process and readjusted 
(when necessary) through addition of small quantities of $\mathrm{NaOH}$ solution $(w=10 \%)$. Based on the deposited mass of $\mathrm{Ni}$, the electrolyte was also replenished (at regular intervals) with nickel and chloride ions.

Hexcel $12 \mathrm{~K}$ AS4 carbon fibre ${ }^{22}$ is polyacrylonitrile (PAN) based product that is delivered to the market as a continuous $12 \mathrm{~K}$ ribbon, in $\approx 3.6 \mathrm{~kg}$ spools. The tow is sized by the manufacturer with an epoxy resin $(0.21 \%$ on average), in order to ease fibre handling and thus to reduce damage to the material. This organic sizing was removed from the fibre (prior to Ni deposition) by heattreatment, carried-out in a muffle (tube) furnace at low oxygen atmosphere (with fibre residence time of 4 hours at $350{ }^{\circ} \mathrm{C}$ ). Another, alternative $\mathrm{CF}$ pre-treatment involved subjection of "as received" Hexcel CF tow to desizing in acetone, which was followed by electrochemical oxidation in $0.5 \mathrm{~mol} \mathrm{dm}^{-3} \mathrm{H}_{2} \mathrm{SO}_{4}$ (performed at an anodic current-density, $j_{\mathrm{a}}=0.5 \mathrm{~mA} \mathrm{~cm}{ }^{-2}$ for $5 \mathrm{~min}$, at room temperature with a $\mathrm{Ti} / \mathrm{Pt}$ auxiliary electrode). The latter (anodic oxidation) treatment leads to functionalization $^{23-26}$ of the CF surface, which process could potentially have a strong impact on both mechanical and electrochemical properties of such-treated carbon fibre tow.

Examination of the NiCCF product started with randomly carried-out selection of NiCCF samples (20 $\mathrm{cm}$ long, collected every $10 \mathrm{~m}$ of the product). Firstly, these fibre specimens were (again) carefully washed in distilled water. Then, they were placed in an excicator for 48 hours, followed by weighing on a precision balance (Sartorius CP224-OCE) to $0.1 \mathrm{mg}$. The above procedure allowed precise evaluation of characteristic nickel loading levels by means of a typical "weighing method". In addition, resistance measurements were performed on selected samples of the $12 \mathrm{~K}$ NiCCF tow, by measuring the voltage drop at constant applied current $(100 \mathrm{~mA})$, over a distance of $20 \mathrm{~cm}$. Both electrical contact points on the NiCCF samples were silverpainted in order to reduce the electrical contact resistance. Fibre resistance was then calculated from equation 1:

$$
R=\frac{V}{I \cdot l}
$$

where:

$R / \Omega \mathrm{cm}^{-1}$ is calculated resistance of the $\mathrm{NiCCF}$ tow sample,

$\mathrm{V} / \mathrm{mV}$ is measured voltage,

$I / \mathrm{mA}$ is applied current,

$l / \mathrm{cm}$ is sample's length.

Subsequently, selected NiCCF samples were sent for SEM analysis, where quality of nickel deposits was verified through tow side viewing, as well as by crosssection examination of the composites, at magnifications between 25 and 3000 . For the cross-sectional examination, tow samples were secured in a holder by epoxy resin. Then, they were ground flat on fine-grade silicon carbide abrasive paper of 2500 grade (Metalogis, Poland). The above procedure was followed by polishing the surface, using 3 and 1 micron polycrystalline diamond suspensions (also from Metalogis). Finally, powder XRD (x-ray diffraction) technique was employed to determine average sizes of crystallite domains $^{27}$ for chosen NiCCF specimens.

In addition, a simple, SEM-supported knot test was used to qualitatively evaluate (and compare) the strength of interfacial adhesion of $\mathrm{Ni}$ (potentially, also its ductility) to the surface of CF filaments. The knot test ${ }^{28,29}$ is a mechanical bending experiment, in which a piece of NiCCF tow is bent sharply enough (a constant load of $500 \mathrm{~g}$ for $5 \mathrm{~s}$ was applied to tie the NiCCF knots in this work) to break the metal coating on the tension side of the bend. Then, the knots are qualitatively examined and compared by the SEM method.

\section{RESULTS AND DISCUSSION}

Table 1 presents an optimized configuration of the carbon fibre electroplating system, which includes electrochemical and all operational parameters that happened to play a key role in the plating process.

\section{Operating Parameters and the Plating Cells' Configuration}

Thus, $\mathrm{pH}$ control of the electrolyte was found to be a crucial element of the plating process. As acidity of the bath kept continuously rising during the course of metal deposition, frequent adjustment of $\mathrm{pH}$ was necessary, where optimum $\mathrm{pH}$ range was found to be around 4.55.0 (for most favorable plating temperature range of 48 $50{ }^{\circ} \mathrm{C}$ ). For more acidic solution, hydrogen evolution reaction (HER) becomes more competitive with reduction of $\mathrm{Ni}^{2+}$ ions at low overvoltages (see the two possible cathodic reactions in equations 2 and 3 , and the corresponding anodic reaction in equation 4). As a consequence, the product (especially at $\mathrm{pH}$ around 3.0) appears to have much less homogeneous distribution of nickel throughout the tow than that produced at higher $\mathrm{pH}$ values (see Figures $4 \mathrm{a}$ and $4 \mathrm{~b}$, correspondingly). At $\mathrm{pH}=$ 3.0 , it is the outer tow sections which primarily become metal-coated (Figure 4a), in relation to the fact that diffusion of evolved (and likely surface-covering) hydrogen bubbles from the centre part of the $\mathrm{CF}$ tow is much more difficult than the corresponding process, but proceeding at the outer tow parts. 


$$
\begin{aligned}
& \mathrm{Ni}^{2+}(\mathrm{aq})+2 \mathrm{e}^{-} \rightleftarrows \mathrm{Ni}^{0}(\mathrm{~s}) \\
& 2 \mathrm{H}^{+}(\mathrm{aq})+2 \mathrm{e}^{-} \rightleftarrows \mathrm{H}_{2}(\mathrm{~g}) \\
& 2 \mathrm{Cl}^{-}(\mathrm{aq})+2 \mathrm{e}^{-} \rightleftarrows \mathrm{Cl}_{2}(\mathrm{~g}) \\
& \text { (insoluble DSA anodes) }
\end{aligned}
$$

With respect to configuration of the plating system, superior quality NiCCF (see later Figure 9a) was produced with the two-cell $(5 \mathrm{~cm}$ each) plating arrangement, equipped with three (or four) sets of highly-polished, SSmade contact rollers (CR). The foremost, spring-loaded pinch CR set, was positioned just over $2 \mathrm{~cm}$ (distance $d$ in Figure 2) away from the DSA anode of the first cell. The above was only possible due to the unique design of the electrolyte overflow compartment, which allowed to minimize an effective, cathode-to-anode voltage (and thus prevented fibre from severe overheating and burning) of the first cell. Then, two (or a single) wrap-type fibre contact roller assemblies were installed, both were mounted on the plater's cover (see also Figure 2 for more details). Another pinchtype CR assembly was fastened at the exit of the second plating cell. The carbon fibre tow was vertically positioned within the plater, giving on optimum cathode-to-anode distance of $\approx 0.5 \mathrm{~cm}$ in both cells. The above configuration of the electroplater allowed to maintain (for the CF line speed of $50 \mathrm{~cm} \mathrm{~min}^{-1}$ ) voltage ranges between $7.0-10.5 \mathrm{~V}$ within the first (nucleation) chamber and $\approx 3.0-5.5 \mathrm{~V}$ within the second nickel deposition cell. The resulting current-densities came to $32.0-42.4 \mathrm{~mA} \mathrm{~cm}^{-2}$ (for the nucleation cell) and 7.1-21.3 $\mathrm{mA} \mathrm{cm}{ }^{-2}$ for the second plating cell (current ranges varied along with the set loading level of $\mathrm{Ni}$ ). In addition, it should be stressed here that employment of much lower current densities (on the order of $20 \mathrm{~mA} \mathrm{~cm}^{-2}$ ) for the primary deposition cell resulted in inferior $\mathrm{Ni}$ deposit homogeneity.
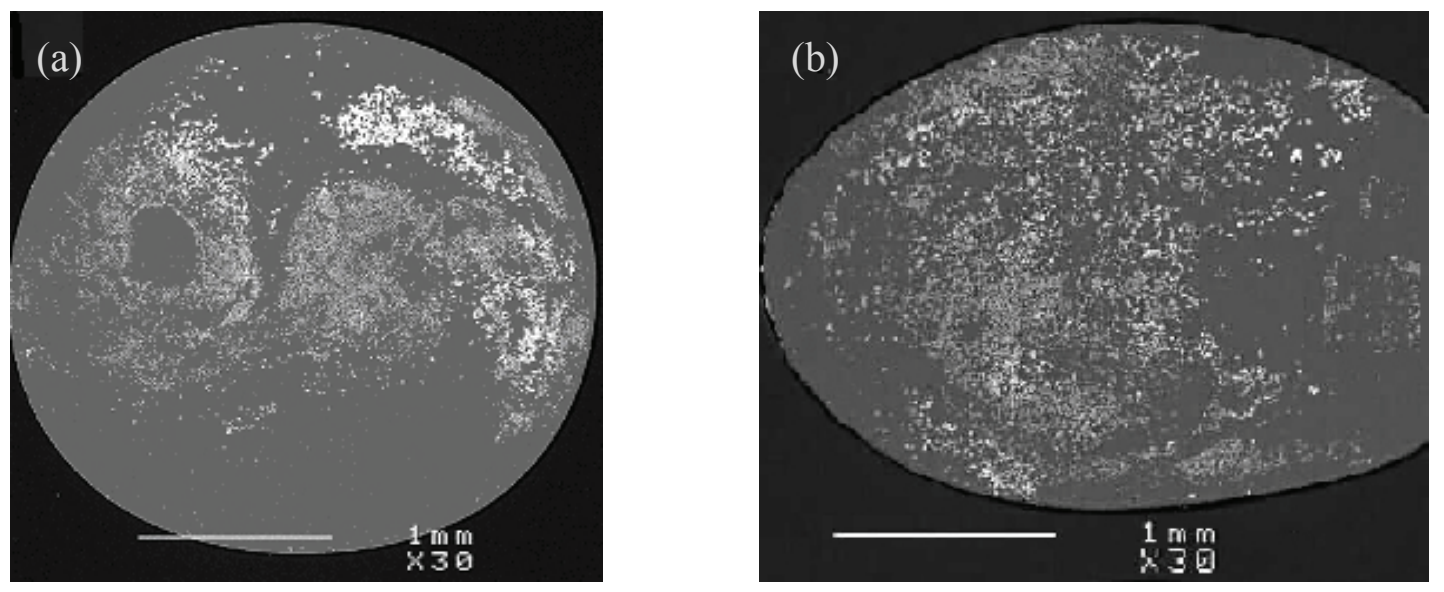

Figure 4. The effect of $\mathrm{pH}$ on the quality of laboratory-electrodeposited NiCCF tow samples (at $w_{\mathrm{Ni}} \approx 30 \%$ ), shown in SEM cross-sectional micrograph pictures for $\mathrm{pH}=3.0$ (a) and $\mathrm{pH}=5.0(\mathrm{~b})$, taken at a given magnification. 

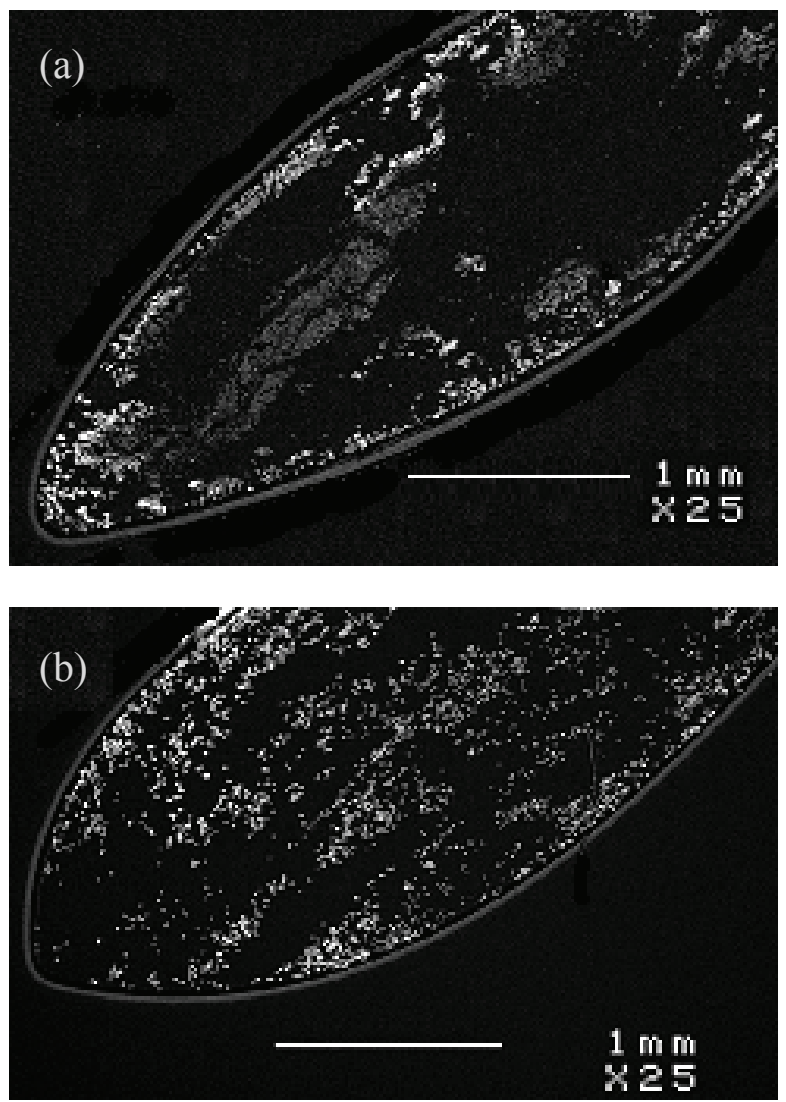

Figure 5. The effect of CF tow's spread on the quality of laboratory-electrodeposited NiCCF tow samples, shown in SEM cross-sectional micrograph pictures for the tow's spread of 0.2 $\mathrm{cm}$ at $w_{\mathrm{Ni}} \approx 36 \%$ (a) and $0.8 \mathrm{~cm}$ at $w_{\mathrm{Ni}} \approx 40 \%$ (b), taken at a given magnification.

On the other hand, the quality of electrodeposited NiCCF significantly depended on the extent of CF tow spreading within the electroplater. As the fibre tow is spread, it forms a ribbon comprised of layers of individual carbon filaments. Then, as the ribbon moves over the contact rollers, each individual carbon fibre changes position and its distance from the cathode roller, leading to variation of contact resistance. For the $12 \mathrm{~K}$ fibre tow and ideal spreading, each carbon filament should be in intimate contact with the cathode roller. Thus, assuming the $12 \mathrm{~K}$ tow of $7 \mu \mathrm{m}$ in diam. fibre (and a single cathode contact roller), for perfect tow spreading (each filament is in contact with the $\mathrm{CR}$ ) the tow spreading should provide about $8.4 \mathrm{~cm}\left(12000 \times 7 \times 10^{-4} \mathrm{~cm}\right)$ wide ribbon. In addition, it should be mentioned that any fibre that is not in direct contact with the cathode roller will have to overcome the radial resistivity of the fibre (or fibres) that shield it from the roller. These noncontact fibres will exhibit significantly reduced currentdensities upon plating, as compared to those being in direct contact with the cathode roller(s). Therefore, the cathode roller configuration should primarily attempt to minimize the electrical contact resistance between the fibres, in order to provide more uniform current distribution within the plating $\mathrm{CF}$ tow. However, an idea behind a practical configuration of the $\mathrm{CF}$ tow spreading within the electroplater is always to compromise between the contact resistance parameter and the extent of fibre damage (the latter effect being directly proportional to the width of the fibre ribbon, in relation to the fibre tension parameter). Significant increase of fibre tension leads to extensive formation of fibre nests inside the plating cells and as a consequence to further increase of fibre tension, and its damage.

In this work, experimentally optimized $\mathrm{CF}$ tow spreading (investigated for ribbon widths between 0.2 and $1.2 \mathrm{~cm}$ ) came to about $0.8 \mathrm{~cm}$ (see the effect of the $\mathrm{CF}$ tow spreading on the quality of the NiCCF product in Figures $5 a$ and $5 b$ ), which for the springloaded pinch $\mathrm{CR}$ assembly (two cathode rollers) means the presence of $\approx 11$ carbon fibre layers between the two cathode rollers (see Figure 6). Thus, for the tow's spread of only $0.2 \mathrm{~cm}$, most of the CF filaments were not in direct contact with the contact roller(s) and as such they did experience dramatically reduced current-densities, as compared to those which were concentrated at the outside of the CF tow. As a result, the tow was primarily plated with nickel at its external regions (see Figure 5a again and contrast this behaviour with that observed in Figure $5 \mathrm{~b}$ ). The above behaviour is in principal similar (although for different reasons) to that observed in Figure $4 \mathrm{a}$ for the plating carried-out at $\mathrm{pH}=3.0$. On the other hand, for the tow's spread over $0.8 \mathrm{~cm}$, a considerable increase of fibre nesting within the electroplating unit was observed over time of metal deposition. The above resulted in gradual deterioration of mechanical properties, as well as the plating quality for the NiCCF composite.

\section{CF Pre-treatments and Bath Additives}

Interestingly, neither selected bath additives nor an electrooxidation pre-treatment applied to the CF tow (see Experimental part above for details) had any significant effect on the quality of such-produced $\mathrm{NiCCF}$ composite (including $\mathrm{Ni}$ coverage on the $\mathrm{CF}$ tow). However, it is important to maintain a relatively low level of sodium lauryl sulphate (e.g. at $\left.0.1-0.2 \mathrm{~g} \mathrm{~L}^{-1}\right)$ in the plating bath. Excessive amounts of the wetting agent tend to induce severe bath foaming (accelerated by the presence of hydrogen bubbles), which leads to nonuniform Ni electrodeposits.

On the other hand, SEM-supported knot tests showed some improvement in the composite mechanical performance for the NiCCF produced with surfaceelectrooxidized $12 \mathrm{~K}$ carbon fibre tow. Here (see Figure 7a), somewhat less extensive delamination and Ni fracturing effects are observed for a knot-tied tow sample, 


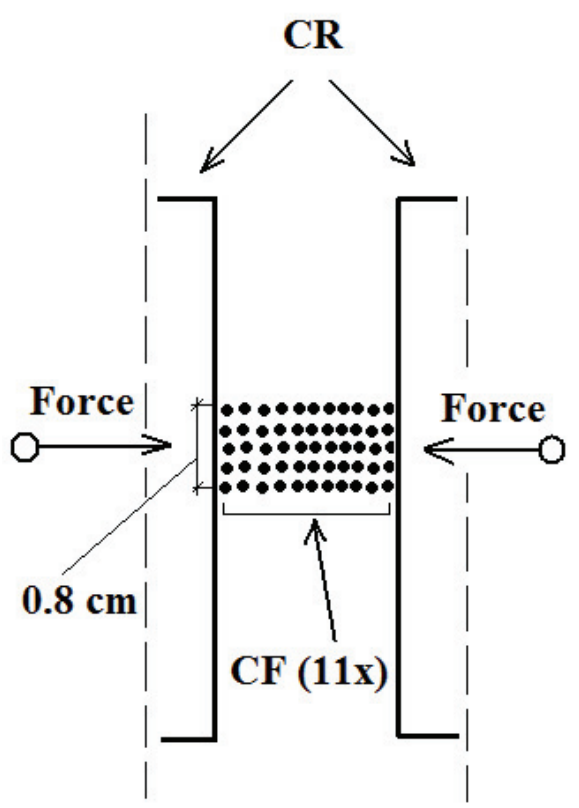

Figure 6. An optimized, pinch-type cathodic CR assembly, with residing 11 layers of carbon fibre filaments.

as compared to that produced with simply heat-treated $\mathrm{CF}$ tow (see Figure $7 \mathrm{~b}$ ). These effects are likely to reflect improved adhesion between the Ni coating and the $\mathrm{CF}$ substrate, in relation to surface functionalization and roughening of electrooxidized $\mathrm{CF}$ tow filaments. It has to be stated here that surface-electrooxidized carbon fibre (see an earlier work from this laboratory in Ref. 30) exhibited significant increase of the electrochemically accessible surface area. Based on the calculated double-layer capacitance $\left(\mathrm{C}_{\mathrm{dl}}\right)$ parameter in Ref. 30, the surface area of $\mathrm{H}_{2} \mathrm{SO}_{4}$-electrooxidized Hexcel $12 \mathrm{~K} \mathrm{CF}$ tow was $\approx 6.6$ times greater than that of the heatpretreated carbon fibre tow.

Nevertheless, it has to be stressed that the knot test is itself somewhat ambiguous in character, as tension and shape of the knot may vary from one sample to another. Thus, the knot method enables only qualitative evaluations and comparisons, and its results have to be discussed with caution.

\section{In-line Monitoring of Ni Loading Levels}

Figure 8 shows the influence of $\mathrm{Ni}$ loading on the NiCCF's electrical resistance parameter. The fibre resistance parameter was derived (see again the Experimental part above for details) in reference to the $\mathrm{Ni}$ loading levels, estimated by means of the weighing method. The resistance measurements were performed for selected run tests, all carried-out with optimized plating setup and bath parameters. It is strongly believed that the abovediscussed correlation could be found suitable for continuous, in-line monitoring of the nickel loading level. Thus, any unwanted change in the re-
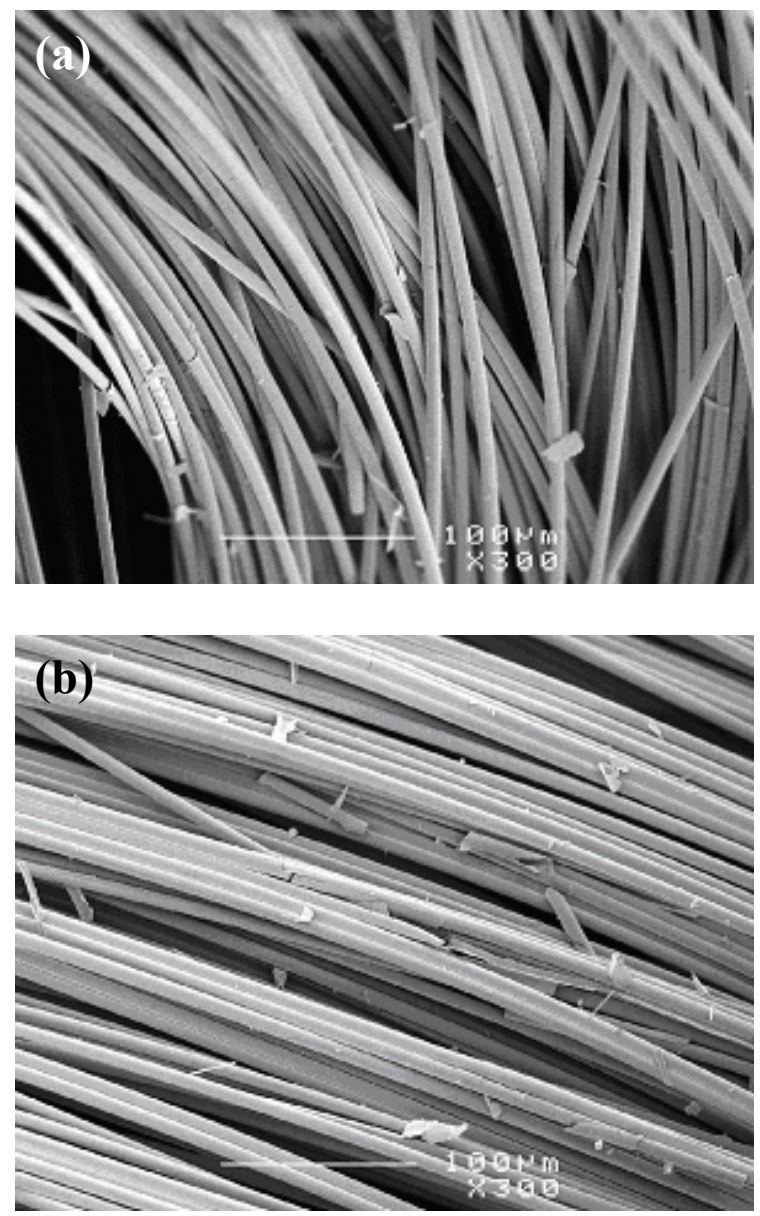

Figure 7. SEM micrograph pictures of knot-tied NiCCF samples (at $w_{\mathrm{Ni}} \approx 40 \%$ ) for NiCCF obtained with surface electrooxidized CF (a) and heat-treated CF tow (b), taken at 300 magnification.

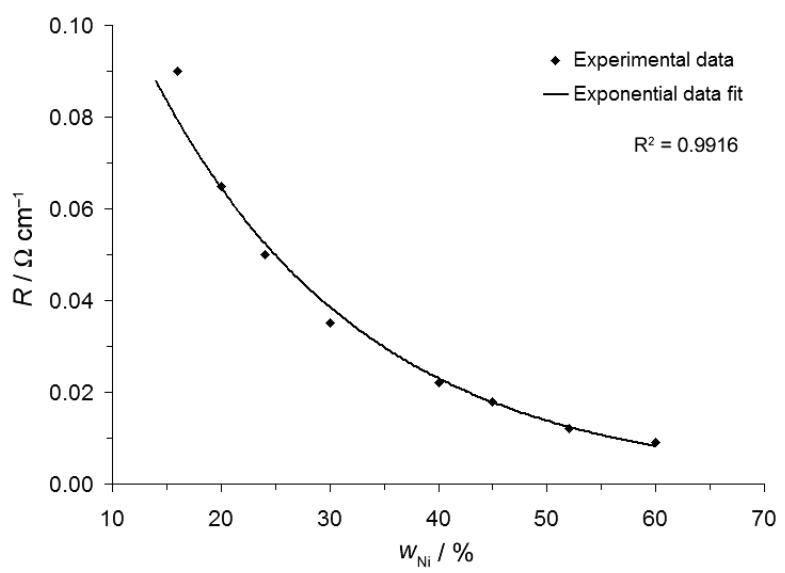

Figure 8. A resistance vs. nickel loading plot for laboratoryelectrodeposited (and optimized) NiCCF tow samples.

sistance parameter (caused by variation in the mass fraction, $w / \%$ of the metal deposit) could immediately be compensated through an appropriate re-adjustment of preset electrical parameters, or the plating line speed. 

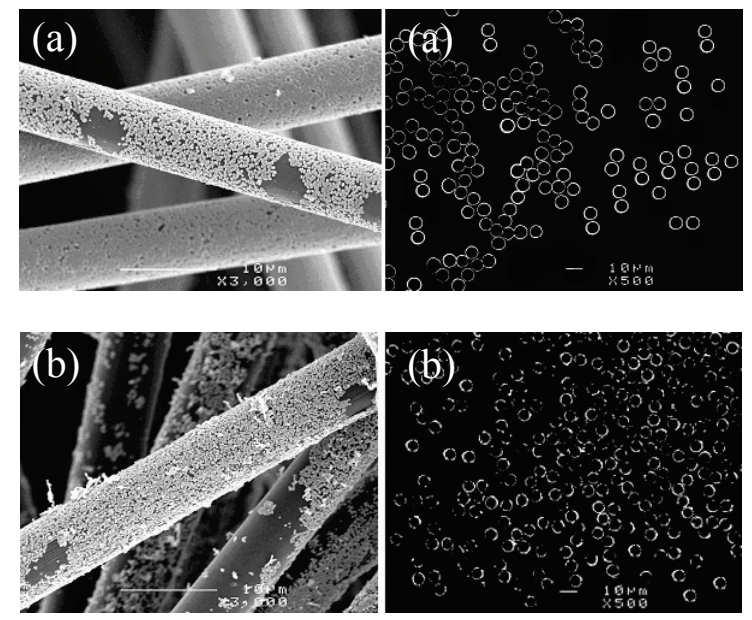

Figure 9. The effect of Ni loading on the quality of laboratory-electrodeposited NiCCF tow samples, shown in SEM micrograph pictures for the Ni loadings of $w_{\mathrm{Ni}} \approx 40 \%$ (a) and $w_{\mathrm{Ni}} \approx 10 \%$ (b), taken at 500 and 3000 magnifications.

However, only NiCCF composites with Ni deposits on the order of $w_{\mathrm{Ni}}=30 \%$ (or higher) exhibited fairly continuous (but non-uniform) metal coverage of individual carbon fibre filaments (see Figure 9a) within the $12 \mathrm{~K} \mathrm{CF}$ tow. Conversely, all NiCCF samples with Ni loadings below $w_{\mathrm{Ni}} \approx 20 \%$ were completely nonhomogeneous, with respect to the surface distribution of the metal deposit (Figure 9b). The above-observed phenomenon strongly supports the idea of severe inconsistency of the applied "electrode potential" (and as a consequence also the Gibbs free energy of activation for the process) within the complex, 12000 -filament CF tow entity.

The thickness of the Ni coating was estimated by measurements conducted on high magnification, crosssectional SEM images. Thus, 100 sample filaments were representatively selected in 10 different areas of the tow $(10 \times 10$ samples $)$. Such estimated thickness of the Ni coating for $w_{\mathrm{Ni}} \approx 50 \%$ composite came to $0.39 \pm$ $0.02 \mu \mathrm{m}$.

\section{CONCLUSION}

Fairly uniform, ultra-thin deposits of $\mathrm{Ni}$ on 12000 filament $\mathrm{CF}$ tow can suitably be produced through a continuous metal electrodeposition process. However, technological aspects of this process are quite complex, in addition to the required advanced knowledge of fibre handling. The most important conclusions that can be drawn from this work are the following:

- Ni deposition should be realized in two steps; initial, nucleation phase proceeds within the first (high current-density is applied, which allows for more uniform nucleation with the fibrils) cell and the grain growth phase takes place in the following plating chamber (both cells together constitute a CF tow electroplating unit)

- superior/homogeneous Ni deposits require:

(i) electrolyte $\mathrm{pH}$ within 4.0 to 5.0 (with proper bath circulation and agitation)

(ii) electrolyte temperature about $50{ }^{\circ} \mathrm{C}$

(iii) $\mathrm{CF}$ tow's spread (optimized in this work at $0.8 \mathrm{~cm}$ for $12 \mathrm{~K} \mathrm{CF}$ tow) should be set to compromise between the electrical contact resistance parameter and the extent of actual fibre damage within the plater (more advanced laboratory designs could capitalize on the application of a professional fibre tension controlling device, e.g. Helman tensioner unit)

(iv) minimized distances between cathodic CRs and DSA anode assemblies (to reduce operational voltages and thus to limit fibre overheating)

(v) electroplater's line speeds between 20 and $100 \mathrm{~cm} \mathrm{~min}^{-1}$ [with cathodic current-densities of $\approx 30-40$ and $10-20 \mathrm{~mA} \mathrm{~cm}^{-2}$ for the nucleation and the grain growth cells, correspondingly (for the line speed of $50 \mathrm{~cm} \mathrm{~min}^{-1}$ )]

- in-line resistance measurement could be utilized for direct monitoring of electrodeposited level/thickness of $\mathrm{Ni}$ on the $\mathrm{CF}$ tow

- applied bath additives and basic CF tow pretreatments had rather insignificant effect on the quality (homogeneity) of such-produced NiCCF composites; however surface electrooxidation treatment applied to CF led to somewhat improved (qualitatively) adhesion between $\mathrm{Ni}$ coating and the carbon fibre surface.

Acknowledgements. Grateful acknowledgement is made by the author of this work to the Commission of the European Communities for financial support of the research described in this paper. This work was financed by the European Union, Marie Curie International Reintegration Grant, acronym "Fibres", contract No.: 031073.

\section{REFERENCES}

1. D. D. L. Chung, J. Mater. Sci. 39 (2004) 2645-2661.

2. D. Markham, Mater. Design 21 (2000) 45-50.

3. S. S. Tzeng and F. Y. Chang, Mater. Sci. Eng. A302 (2001) 258-267.

4. D. D. L. Chung, Carbon 39 (2001) 279-285.

5. S. Y. Fu, B. Lauke, E. Mader, C. Y. Yue, and X. Hu, Composites: Part A 31 (2000) 1117-1125.

6. L. Bertolini, F. Bolzoni, T. Pastore, and P. Pedeferri, Cement and Concrete Research 34 (2004) 681-694.

7. P. J. Moreland and F. L. J. de Peuter, US Patent No. 5,364,511 (1994). 
8. J. K. Lee, K. W. An, J. B. Ju, B. W. Cho, W. I. Cho, D. Park, and K. S. Yun, Carbon 39 (2001) 1299-1305.

9. V. A. Ettel, E. Krause, and J. Van Wagner, Can. Patent No. 1,333,547 (1994).

10. C. Y. Huang and J. F. Pai, Eur. Polym. J. 34(2) (1998) 261-267.

11. S. J. Park, Y. S. Jang, and K. Y. Rhee, J. Colloid Interface Sci. 245 (2002) 383-390.

12. C. Y. Huang, W. W. Mo, and M. L. Roan, Surf. Coat. Technol. 184 (2004) 163-169.

13. S. S. Tzeng and F. Y. Chang, Mater. Sci. Eng. A302 (2001) 258-267.

14. L.G. Morin, US patent No. $\mathbf{4 , 6 0 9 , 4 4 9}$ (1986).

15. L.G. Morin, US patent No. $\mathbf{4 , 6 6 1 , 4 0 3 ~ ( 1 9 8 6 ) . ~}$

16. L.G. Morin, US patent No. $\mathbf{4 , 6 8 0 , 0 9 3 ~ ( 1 9 8 6 ) . ~}$

17. L.G. Morin, US patent No. 4,909,910 (1986).

18. L.G. Morin, US patent No. 4,942,090 (1986).

19. L.G. Morin, US patent No. 4,976,828 (1986).

20. F. A. Lowenheim in Modern Electroplating, $4^{\text {th }}$ ed., M. Schlesinger and M. Paunovic (Eds.), John Wiley \& Sons, Inc., New York 2000.
21. G. Di Bari, Metal Finishing 100(1) (2002) 257-274.

22. HexTowTM AS4C Carbon Fiber. Product Data, http://www.hexcel.com (2010).

23. S. J. Park and M. H. Kim, J. Mater. Sci. 35 (2000) 1901-1905.

24. Z. R. Yue, W. Jiang, L. Wang, S. D. Gardner, and C. U. Pittman, Carbon 37 (1999) 1785-1796.

25. M. Ishifune, R. Suzuki, Y. Mima, K. Uchida, N. Yamashita, and S. Kashimura, Electrochim. Acta 51 (2005) 14-22.

26. J. Gulyas, E. Foldes, A. Lazar, and B. Pukanszky, Composites: Part A 32 (2001) 353-360.

27. F. Sanchez-Bajo, A. L. Ortiz, and F. L. Cumbrera, Acta Materialia 54 (2006) 1-10.

28. Y. Ulcay and S. Altun, Fibers and Polymers 5(2) (2004) 156-159.

29. ASTM D2256/D2256M-09, Standard test method for tensile properties of yarns by the single-strand method - ASTM Standards (2009).

30. B. Pierozynski and L. Smoczynski, J. Electrochem. Soc. 155 (8) (2008) C427-C436. 